\title{
Response to exclusive right middle lobe treatment with endobronchial valves: a case report
}

\section{Introduction}

Emphysema is a condition of the lung mainly due to tobacco smoking characterised by abnormal, permanent enlargement of airspaces distal to the terminal bronchiole, accompanied by the destruction of their walls. Symptoms may include coughing, wheezing and shortness of breath. Treatment options may include bronchodilators, supplemental oxygen, vaccination, pulmonary rehabilitation and nutrition therapy. Depending on the severity of the emphysema, other invasive or minimally invasive options can be offered such as lung transplantation for end-stage disease, lung volume reduction surgery (LVRS) for heterogeneous, upper lobe-predominant emphysema and giant bullae, and bronchoscopic lung volume reduction (BLVR) in selected patients. Based on the positive results of multiple randomised controlled trials demonstrating improvements in pulmonary function, exercise capacity and quality of life [1-4], BLVR using Zephyr endobronchial valves (EBVs; PulmonX, Redwood City, CA, USA) has been approved for the treatment of patients with severe emphysema and little to no collateral ventilation.

\section{Case presentation}

A 57-year-old male, former smoker (50 packyears), with no other medical history than severe COPD, was referred to our institution to discuss the

@ERSpublications

Isolated right middle lobe (RML) lung volume reduction using endobronchial valves can lead to significant improvements in appropriately selected patients, with highly hyperinflated RML and preserved upper and lower lobes https://bit.ly/3rlCgTn management of his chronic respiratory failure. His body mass index (BMI) was $21 \mathrm{~kg} \cdot \mathrm{m}^{-2}$. Dyspnoea was reported as modified Medical Research Council (mMRC) scale 4 despite optimal treatment including inhaled therapeutics and formal rehabilitation programmes. Physical examination revealed chest hyperinflation and reduced breath sounds on chest auscultation. St George's Respiratory Questionnaire (SGRQ) score was 78.4 (score between 0 and 100, designed to measure the impact on general health, daily life and perceived well-being in patients with COPD).

Pulmonary function tests showed:

- forced vital capacity (FVC) of $2.3 \mathrm{~L}(49 \%$ predicted),

- forced expiratory volume in $1 \mathrm{~s}\left(\mathrm{FEV}_{1}\right)$ of $0.8 \mathrm{~L}$ (23\% predicted),

- $\mathrm{FEV}_{1} / \mathrm{FVC}$ ratio of 0.35 , and

- residual volume (RV) of $8.0 \mathrm{~L}$ (340\% predicted).

Diffusing capacity of the lung for carbon monoxide ( $\left.D_{\mathrm{LCO}}\right)$ was $21 \%$ of predicted. The $6-\mathrm{min}$ walk distance (6MWD) was $250 \mathrm{~m}$ under $4 \mathrm{~L} \cdot \mathrm{min}^{-1}$ oxygen. BODE (BMI, airflow obstruction, dyspnoea, exercise capacity) index was 8.

Chest computed tomography $(\mathrm{CT})$ scan revealed severe emphysema which was homogeneous except for a surprisingly hyperinflated and destroyed right middle lobe (RML) whose volume was measured at $2350 \mathrm{~mL}$ (figure 1a). Quantitative tomoscintigraphy showed homogeneous distribution of perfusion
Cite as: Villeneuve T, Fumat R, Héluain V, et al. Response to exclusive right middle lobe treatment with endobronchial valves: a case report. Breathe 2021; 17: 210108 .

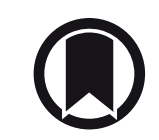

CrossMark 

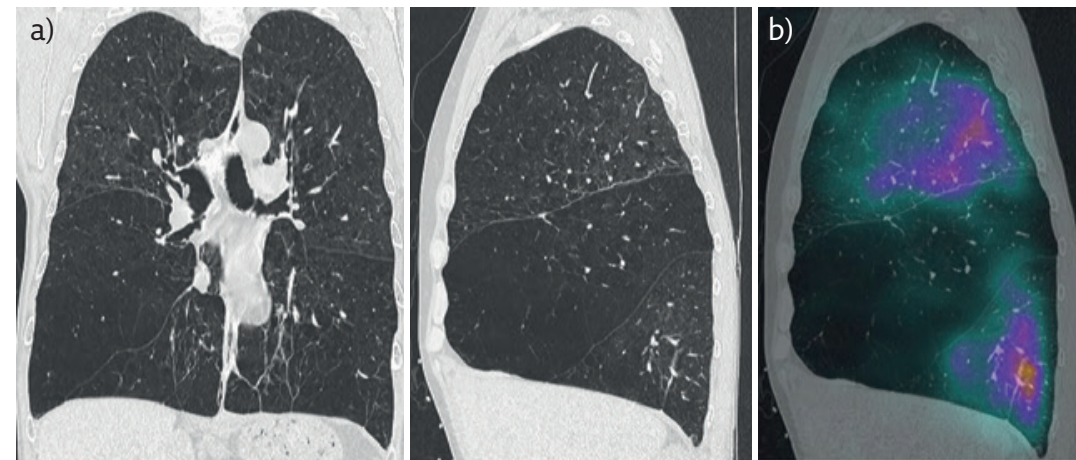

Figure 1 a) Pre-treatment CT scan. b) Pre-treatment sagittal ventilation/perfusion tomoscintigraphy showing abolished perfusion in the right middle lobe contrasting with preserved right upper and lower lobe perfusions.

between all "major" lobes, with a relatively preserved perfusion in the right upper and lower lobes, but an abolished perfusion in the RML (figure 1b).

\section{Task 1}

What are the treatment options?

Go to Answers $>>$

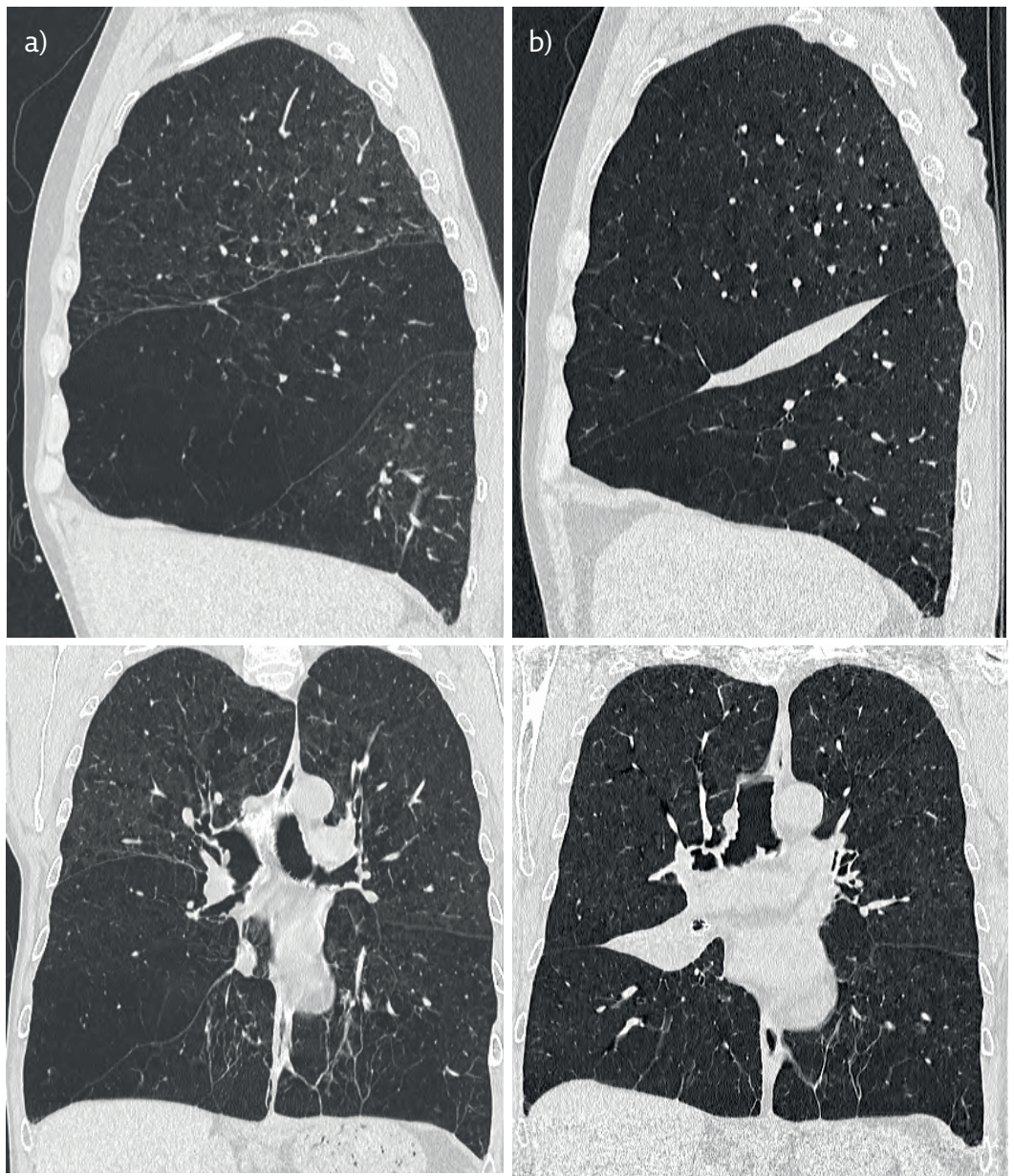

Figure 2 CT scan a) before and b) after EBV treatment showing the right middle lobe atelectasis and expansions of the right upper and lower lobes. Before EBV treatment: RV $8000 \mathrm{~mL}$, FVC $2300 \mathrm{~mL}, F E V_{1} 800 \mathrm{~mL}, \mathrm{mMRC}$ scale 4, 6MWD $250 \mathrm{~m}$, SGRQ 78.4 and BODE index 8. After EBV treatment: RV $5900 \mathrm{~mL}(-2100 \mathrm{~mL})$, FVC $3500 \mathrm{~mL}$ (+52\%), FEV $1200 \mathrm{~mL}$ (+50\%), mMRC scale 2, 6MWD $360 \mathrm{~m}$, SGRQ 37.8 and BODE index 5.

\section{Task 2}

What additional analysis would you suggest if you decide to perform BLVR with valves?

Go to Answers $>>$

Task 3

What treatment option would you take?

Go to Answers $>>$

\section{Ongoing management}

Two EBVs were placed in the RML (one 4.0 in RB4, one 5.0 in RB5) through a flexible bronchoscope under general anaesthesia after confirmation of the absence of collateral ventilation using the Chartis system (PulmonX, Redwood City, CA, USA). The patient was discharged from the hospital after 3 days. 6 weeks after the procedure, the CT scan showed complete atelectasis of the RML (figure 2b).

This significant target lung volume reduction (TLVR) resulted in expansions of both the right upper and lower lobes (figure $2 \mathrm{~b}$ ) and a deep reduction in $\mathrm{RV}(-2100 \mathrm{~mL})$.

This translated into significant improvements in:

- FVC (from 2300 to $3500 \mathrm{~mL},+52 \%$ ),

- $\mathrm{FEV}_{1}$ (from 800 to $1200 \mathrm{~mL},+50 \%$ ),

- dyspnoea which dropped to mMRC scale 2,

- quality of life with SGRQ score decreased from 78.4 to 37.8 ,

- $6 \mathrm{MWD}$ (from $250 \mathrm{~m}$ to $360 \mathrm{~m}$ under $4 \mathrm{~L} \cdot \mathrm{min}^{-1}$ oxygen), and

- BODE index which decreased from 8 to 5 .

\section{Discussion}

The most destructed lobes with intact fissures among the major lobes (upper and lower) are usually chosen as targets for a BLVR approach; the RML is treated only in addition to the right upper lobe when the small fissure is not complete. Very few data are available regarding isolated treatment of the RML. We report herein successful treatment of RML alone in a patient with the perfect RML as a target lobe and review the existing BLVR literature regarding this unusual presentation.

No data are available from the main randomised controlled trials regarding isolated BLVR of the RML [1-4]. The STELVIO trial was the only one where isolated RMLs were treated, but results were not shown per treatment-target groups [1]. Exclusive RML treatment is commonly considered inappropriate for two main reasons: 1 ) RML is rarely the most destroyed in emphysema, and 2) the expected benefit may be considered negligible due to a smaller physiological volume. Our patient met all the clinical criteria for BLVR [5], but was initially thought to have contraindications due to the absence of a clear target, in particular on tomoscintigraphy. 
Table 1 Characteristics of patients with bronchoscopic RML reduction with EBVs

\begin{tabular}{|c|c|c|c|c|c|c|}
\hline Case reports & This case & Case 2 [8] & Case 3 [8] & Case 4 [8] & Case 5 [7] & Case 6 [6] \\
\hline \multicolumn{7}{|c|}{ Demographics and clinical data } \\
\hline Sex & Male & Male & Female & Male & Male & Female \\
\hline Age, years & 57 & 52 & 66 & 50 & 65 & 65 \\
\hline Smoking status (pack-years) & Past (50) & Past (35) & Past (20) & Past & Past (80) & Past (20) \\
\hline EBV target & $\begin{array}{l}\text { RML } \\
\text { emphysema }\end{array}$ & RML bulla & RML bulla & RML bulla & $\begin{array}{l}\text { RML bulla } \\
15.0 \times 10.1 \mathrm{~cm}\end{array}$ & $\begin{array}{c}\text { RML bulla } \\
12.7 \times 10.1 \mathrm{~cm}\end{array}$ \\
\hline \multicolumn{7}{|l|}{ Pulmonary function tests } \\
\hline $\mathrm{RV}, \mathrm{L}$ (\% pred) & $8(340)$ & $5.37(215.8)$ & & & $6.43(275)$ & $3.54(182)$ \\
\hline Follow-up, months & 2 & 6 & 6 & 6 & 2 & 12 \\
\hline mMRC class & $2(+2)$ & & & & & \\
\hline RV, L (gain) & $5.9(-2.1 \mathrm{~L})$ & & & & $4.74(-1.69 \mathrm{~L})$ & $2.89(-0.65 \mathrm{~L})$ \\
\hline FVC, L (gain, L and \%) & $\begin{array}{c}3.5 \\
(+1.2 L,+52 \%)\end{array}$ & & & & & \\
\hline $\mathrm{FEV}_{1}, \mathrm{~L}$ (gain, $\mathrm{mL}$ and \%) & $\begin{array}{c}1.2 \\
(+400 \mathrm{~mL} \\
+50 \%)\end{array}$ & $\begin{array}{c}1.75 \\
(+680 \mathrm{~mL} \\
+63 \%)\end{array}$ & $\begin{array}{c}1.03 \\
(+320 \mathrm{~mL} \\
+45 \%)\end{array}$ & $\begin{array}{c}0.83 \\
(+90 \mathrm{~mL} \\
+12 \%)\end{array}$ & $\begin{array}{c}0.58 \\
(+170 \mathrm{~mL} \\
+41 \%)\end{array}$ & $\begin{array}{c}0.86 \\
(+120 \mathrm{~mL} \\
+16 \%)\end{array}$ \\
\hline $\begin{array}{l}\text { 6MWD, } m \text { (change } m \text { and \% } \\
\text { gain) }\end{array}$ & $\begin{array}{c}360 \\
(+110 \mathrm{~m}, 31 \%)\end{array}$ & & & & & $300(+70 \mathrm{~m})$ \\
\hline
\end{tabular}

However, we decided to target the RML alone based on its unusual hyperinflation, the relatively preserved right upper lobe and right lower lobe, and the absence of collateral ventilation on the RML Chartis evaluation. Usually, the RML is only treated in combination with the right upper lobe, but in cases of a severely hyperinflated and destructed RML with intact fissures, treatment might be considered, EBV therapy being a good example of personalised medicine.

After EBV implantation, we observed noteworthy clinical and functional improvements (figure 2). All items improved well above minimal clinically important differences, with in particular an unexpected $2100 \mathrm{~mL}$ RV decrease for an exclusive RML treatment.
To the best of our knowledge, this is only the sixth reported case of isolated BLVR of the RML (table 1) [6-8]. In other reports, BLVR has been used to treat giant bullae in the RML with clinical improvement in four out of five patients (650 to $1700 \mathrm{~mL}$ RV decreases; $170 \mathrm{~mL}$ median $\mathrm{FEV}_{1}$ increase $(120 \mathrm{~mL}(+16 \%)$ to $600 \mathrm{~mL}(+60 \%))$ (table 1) [6-8]. The outcomes observed in our case agree with what was observed in these previous cases $[5,9,10]$, providing further evidence that the RML is "targetable" by BLVR.

In conclusion, the RML can be chosen as the sole target for BLVR in appropriately selected patients, with highly hyperinflated RML and preserved upper and lower lobes.

\section{Answers}

\section{Answer 1}

- Pursue medical treatment and respiratory rehabilitation.

- LVRS of RML to reduce the size of the over-inflated lung.

- Lung transplantation for this patient with end-stage COPD.

- BLVR using EBVs [1-4]. 


\section{Answer 2}

The StratX software (PulmonX, Redwood City, CA, USA) analyses the density and volume of each lobe, as well as the fissures integrity. It represents a valuable noninvasive screening tool for candidates for BLVR and helps choosing the target lobe.

It confirmed the homogeneity of the emphysema (5\% and $2 \%$ destruction gradients between the upper and lower lobes for the right and left lungs, respectively), but a highly destroyed (85\% and $70 \%$ of parenchyma below 910 and 950 Hounsfield units (HU) density, respectively) and hyperinflated $(2350 \mathrm{~mL}$ ) RML. Large and small fissures integrity scores were $100 \%$ and $94 \%$, respectively.

\section{Answer 3}

We decided to perform our first isolated treatment by BLVR of the RML due to its unusual volume, the preserved perfusion on all major lobes and low diffusing capacity.

\section{Affiliations}

\section{Thomas Villeneuve ${ }^{1}$, Romane Fumat ${ }^{1}$, Valentin Héluain ${ }^{1}$, Pierre Pascal ${ }^{2}$, Gavin Plat ${ }^{1}$, Nicolas Guibert ${ }^{1}$}

${ }^{1}$ Pulmonology Dept, Larrey University Hospital, Toulouse, France. ${ }^{2}$ Radiology and Nuclear Medecine Dept, Rangueil University Hospital, Toulouse, France.

\section{Conflict of interest}

None declared.

\section{References}

1. Klooster K, ten Hacken NHT, Hartman JE, et al. Endobronchial valves for emphysema without interlobar collateral ventilation. N Engl I Med 2015; 373: 2325-2335.

2. Kemp SV, Slebos D-J, Kirk A, et al. A multicenter randomized controlled trial of Zephyr endobronchial valve treatment in heterogeneous emphysema (TRANSFORM). Am J Respir Crit Care Med 2017; 196: 1535-1543.

3. Valipour A, Slebos D-J, Herth F, et al. Endobronchial valve therapy in patients with homogeneous emphysema. Results from the IMPACT Study. Am J Respir Crit Care Med 2016; 194: 1073-1082

4. Davey C, Zoumot Z, Jordan S, et al. Bronchoscopic lung volume reduction with endobronchial valves for patients with heterogeneous emphysema and intact interlobar fissures (the BeLieVeR-HIFi study): a randomised controlled trial. Lancet 2015; 386: 1066-1073.

5. Slebos D-J, Shah PL, Herth FJF, et al. Endobronchial valves for endoscopic lung volume reduction: best practice recommendations from expert panel on endoscopic lung volume reduction. Respiration 2017; 93: 138-150

6. Hou G, Wang W, Wang Q, et al. Bronchoscopic bullectomy with a one-way endobronchial valve to treat a giant bulla in an emphysematic lung: a case report. Clin RespirJ 2016; 10: 657-660.

7. Gu Lee E, Rhee CK. Bronchoscopic lung volume reduction using an endobronchial valve to treat a huge emphysematous bullae: a case report. BMC Pulm Med 2019; 19: 92.

8. Tian Q, An Y, Xiao B-B, et al. Endobronchial valve to treat large bulla at right middle lobe in chronic obstructive pulmonary disease patients. J Thorac Dis 2015; 7: E374-E377.

9. Deslée $\mathrm{G}, \mathrm{Mal} \mathrm{H}$, Dutau $\mathrm{H}$, et al. Lung volume reduction coil treatment vs usual care in patients with severe emphysema: the REVOLENS randomized clinical trial. JAMA 2016; 315: 175.

10. Sciurba FC, Criner GJ, Strange C, et al. Effect of endobronchial coils vs usual care on exercise tolerance in patients with severe emphysema: the RENEW randomized clinical trial. JAMA 2016; 315: 2178. 